\title{
ANTROPOLOGIA DA SAÚDE E DOENÇA: CONTRIBUIÇÕES PARA OS SERVIÇOS PÚBLICOS DE SAÚDE
}

\author{
ARTIGO ORIGINAL \\ LARRUBIA, Bruno Costa ${ }^{1}$ \\ JUNIOR, Nelson Edson da Silva ${ }^{2}$
}

FREITAS, Isadora Mascarenhas de ${ }^{3}$

LARRUBIA, Bruno Costa. JUNIOR, Nelson Edson da Silva. FREITAS, Isadora Mascarenhas de. Antropologia da saúde e doença: contribuições para os serviços públicos de saúde. Revista Científica Multidisciplinar Núcleo do Conhecimento. Ano 04, Ed. 08, Vol. 04, pp. 05-28. Agosto de 2019. ISSN: 2448-0959, Link de acesso: https://www.nucleodoconhecimento.com.br/administracao/servicospublicos

\section{RESUMO}

Embora a maioria dos estudos sobre o acesso aos serviços públicos de saúde tenha se concentrado no campo da epidemiologia, objetivamos, neste estudo, investigar as contribuições da Antropologia para os serviços públicos de saúde através da representação social de saúde e doença, do conceito de humanização do atendimento, da saúde de proximidade e demais conceitos que tem surgido no encontro da antropologia com as ciências da saúde. Consideramos que todo processo de saúde e doença pertence a um sistema sociocultural, ao mesmo tempo que é atravessado por questões institucionais, legais e epidemiológicos. A saúde e doença

\footnotetext{
${ }^{1}$ Doutor em Ciências Sociais (PUC-Rio), Mestre em Psicologia Clínica (PUC-Rio), Bacharele em Psicologia (PUC-Rio), Graduando em Administração Pública (UFF).

${ }^{2}$ Graduando em Administração Pública (UFF).

${ }^{3}$ Graduando em Administração Pública (UFF).
} 
são experiências corporais vividas de modo biológico, religioso, histórico, emocional e socioeconômico. Neste sentido, as transformações legais no sistema de saúde a partir da Constituição de 1988, principalmente com a criação do Sistema Único de Saúde - SUS - colocaram em foco a "humanização" do tratamento em saúde, trazendo ao centro do debate a questão humana, logo, antropológica, sobre a demanda e o acesso aos serviços públicos de saúde. Deste modo, buscamos apresentar sinteticamente as transformações legais e estruturais no sistema de saúde brasileiro nos últimos 30 anos, pela qual passamos a revalorizar a contribuição da Antropologia para o debate acerca da saúde e da doença também como fenômeno cultural e extraímos deste debate contribuições aos serviços públicos que podem auxiliar a construção de novas políticas públicas, mais eficazes e eficientes no atendimento aos usuários dos serviços de saúde. Um dos pontos centrais é entender o percurso do paciente dentro dos serviços de saúde em busca da sua cura denominado de itinerário terapêutico - e como este é elaborado através da atenção dada ao corpo enquanto fenômeno social e individual. Portanto, são as maneiras culturalmente elaboradas de cuidar da saúde que norteiam as demandas por serviços de saúde, rompendo assim com a lógica econômica na saúde ao descartar a mera explicação da oferta e demanda como fator principal para as decisões dos pacientes. O resultado que buscamos atingir é a compreensão dos princípios de funcionamento da busca por cuidados terapêuticos e uma interpretação antropológica acerca das experiências de saúde e doença, e como este entendimento pode contribuir para melhoria dos serviços de saúde pública, principalmente a partir da vivência do usuário.

Palavras-chave: Saúde e doença, cultura e tratamento, saúde pública, atendimento.

\section{INTRODUÇÃO}

O conceito de saúde e doença formam um binômio que tem sua fundamentação pautada no viés econômico, político e cultural. Podemos facilmente inferir que cada indivíduo adota um conceito sobre o que é saúde, o que pode variar dependendo da idade do indivíduo, de sua visão religiosa, de seus valores pessoais, classe social e contexto histórico, entre outros fatores (BERGER, LUCKMANN, 2002). Do mesmo modo podemos deduzir que tal indivíduo extraí tais convicções e crenças sobre a 
saúde a partir de seus grupos de convívio, família, religião, etc., nos remetendo ao dualismo indivíduo e sociedade. Para a Organização Mundial de Saúde (OMS) a definição de saúde deve considerar um estado de completo bem-estar físico, mental e social, e não apenas ausência de doenças e patologias. Assim, tais estados elencados pela OMS passam a fazer parte dos termos determinantes para a sistematização da saúde (SCILIAR, 2007). A assistência à saúde no Brasil passou por profundas transformações desde a Constituição de 1988 que em seu artigo 196 consagrou o Sistema Único de Saúde - SUS - como modelo público, universal e gratuito de acesso à saúde para os brasileiros (COHN e ELIAS, 1996).

A antropologia voltada para a saúde (CSORDAS, 2003) entende o corpo do paciente que busca auxílio médico como solo existencial do sujeito e da cultura, no qual cada indivíduo experimenta as múltiplas oportunidades de "fazer-se humano" a partir de possibilidades culturalmente ofertadas. Assim, a corporeidade passa a ser não apenas essencialmente biológica, mas também, religiosa, linguística, histórica, cognitiva, emocional e artística, deslocando o eixo da questão da cura para fora da tentativa apenas de eliminar algo indesejado (gordura, tumor, vírus, bactéria, etc) e colocandoa a partir da transformação da pessoa durante o processo de cura. O corpo é uma falsa evidência (LE BRETON, 2010) no sentido de ser um objeto natural, mas é uma forte evidência no sentido de ser "o primeiro e mais natural objeto técnico, e ao mesmo tempo meio técnico do homem é seu corpo" (MAUSS, 2003, p.217).

Deste modo, o antropólogo Augé (1986) chama a atenção para a relevância de se acompanhar dentro do itinerário terapêutico toda a trajetória do paciente - antes, durante e depois - do atendimento de saúde, uma vez que o atendimento em saúde deve também ser analisado em sua função simbólica de ritual de passagem. Este tipo de análise coloca em evidência as experiências de vida, as trajetórias pessoais e os projetos individuais formulados e elaborados dentro de um campo de possibilidades, "circunscrito histórica e culturalmente, tanto em termos da própria noção de indivíduo como dos temas, prioridades e paradigmas culturais existentes" (VELHO, 1990, p. 27), no qual o binômio saúde/doença compõe uma relação dialógica (OTTA e QUEIROZ, 2000; MERLEAU-PONTY, 1973). 
É neste sentido que passaremos a examinar contribuições da Antropologia para o campo das ciências da saúde, desde as discussões teóricas até as práticas de atendimento dos usuários (GARNELO e LANGDON, 2005). Entre as inúmeras reflexões da Antropologia pertinentes para o campo da saúde, podemos destacar neste artigo: o impacto dos conceitos antropológicos na formulação do SUS; o debate sobre saúde e doença para além da figura do médico e do hospital; a importância da compreensão dos itinerários terapêuticos; a relação entre indivíduo e sociedade no adoecimento; os modos de navegação através das instituições de saúde e finalmente as contribuições da antropologia para a área das políticas públicas de saúde pública.

\section{OBJETIVO}

O objetivo deste artigo é investigar a representação social de saúde e doença a partir de uma perspectiva antropológica, construindo assim as contribuições da Antropologia para o aprimoramento dos serviços públicos de saúde. A reflexão sobre a trajetória dos pacientes em busca dos serviços de saúde - itinerários terapêuticos - nos permite melhor analisar os padrões de utilização destes serviços, revelando conceitos, crenças e comportamentos chaves para o aperfeiçoar o sistema de atendimento, adequando sua dinâmica ao ethos social de relação entre saúde e doença.

\section{METODOLOGIA}

Nessa perspectiva, para se desenvolver tal ensaio teórico faz-se necessário traçar um caminho metodológico coerente com que se deseja investigar (MINAYO, 2006; POLIT; BECK; HUNGLER, 2011). A partir do exposto, para atender o objeto de pesquisa em questão, elegeu-se realizar uma revisão integrativa. Esta modalidade de pesquisa é uma abordagem metodológica mais ampla, que permite a inclusão de estudos experimentais e não experimentais, associações da literatura teórica e empírica, incorporar definições de conceitos, revisão de teorias e evidências, para uma compreensão completa do fenômeno analisado. Tal método inclui a análise de estudos que fornecem suporte para a tomada de decisões racional e melhoria da prática profissional (SOUZA; SILVA; CARVALHO, 2010). 
A revisão integrativa da literatura possibilita a realização de uma síntese do conhecimento científico publicado, prestando-se como uma ferramenta criteriosa da produção científica. A construção metodológica da revisão integrativa se deu em cinco etapas distintas, viabilizando a confiabilidade dos resultados e o rigor científico, foram realizadas as seguintes etapas: 1) elaborou-se o tema do estudo; 2) realizou-se a pesquisa bibliográfica; 3) organizou-se os dados coletados; 4) interpretou-se e avaliou-se os resultados dos estudos; 5) apresentou-se e divulgou-se a revisão (MARCONI; LAKATOS, 2002).

\section{O SISTEMA ÚNICO DE SAÚDE NO BRASIL}

O SUS tem como princípios e diretrizes a universalidade de atendimento, ou seja, todas as pessoas têm direitos à saúde independente de cor, classe social, crenças ou sexo; a integralidade no atendimento, o que nos remete ao fato de que o paciente precisa ser visto como um todo, e se necessário, ser enviado para tratamento com outros profissionais, o que proporciona a integralidade do atendimento e finalmente $o$ princípio da igualdade/equidade, preconizando que todos os cidadãos têm direito assistência à saúde, sem preconceitos ou privilégios, tendo o intuito de diminuir a desigualdade proporcionando um atendimento personalizado segundo as necessidades de cada usuário (BRASIL, 2015).

Para garantir essas premissas o SUS estabeleceu quatro importantes princípios organizativos fundamentais. O primeiro deles é a regionalização/hierarquização dos serviços, ou seja, os serviços devem ser organizados mediantes níveis crescentes de complexidade limitados a uma determinada área geográfica. O segundo ponto é a descentralização e o comando único: se trata da redistribuição do poder e da responsabilidade entre as três esferas do governo (federal, estadual e municipal), que possuem autonomia para tomar decisões em sua administração. Vale ressaltar que atualmente, os municípios são responsáveis pelo atendimento integral ao usuário. Em terceiro lugar, o SUS preconiza a participação da população, que se dá através dos conselhos e das conferências de saúde, para que os cidadãos possam expressar suas opiniões e sugestões sobre controle, avaliação e execução das políticas de saúde. Finalmente, o SUS trabalha com o conceito de intersetorialidade, o que implica na 
ideia de que a saúde vai além do atendimento médico, pois, envolve ações de diferentes setores, como trabalho, lazer, habitação, educação etc. (SOUSA, 2014).

A partir dessa nova perspectiva de saúde, é criada a Estratégia de Saúde da Família (ESF), em que equipes são formadas com objetivo de estabelecer vínculo com a população, dividindo a responsabilidade do cuidado através da continuidade da atenção. Esta intervenção coloca a família e o seu contexto socioespacial como centro do cuidado, o que possibilita que as equipes atuem principalmente nas unidades básicas de saúde, nas residências e na mobilização da comunidade, sendo a porta de entrada para um sistema hierarquizado e regionalizado (SOUSA, 2014).

As políticas de atenção básica também são entendidas como atenção primária de saúde, que são a referência para o primeiro encontro do indivíduo ou comunidade com - SUS na esfera municipal, direcionando a atuação para a promoção e proteção da saúde. Neste sentido, o Programa de Saúde da Família busca intervir a partir da primazia do menor grau de complexidade, tecnologia e equipamento, apropriados a atender a maioria das demandas do indivíduo e da sociedade (BOING \& CREPALDI, 2010).

O Ministério da Saúde criou o Núcleo de Apoio à Saúde da Família (NASF) com a perspectiva de apoiar a inclusão e o desenvolvimento da Estratégia Saúde da Família nas redes de serviços, ampliando sua resolubilidade e reformando o processo de territorialização segundo (Portaria MS n. 154, de 24 de janeiro de 2008). No NASF, o principal instrumento de trabalho é a base matricial (frente de caráter pedagógico e de apoio a ESF), no qual são previstas novas áreas de estratégias.

Na Atenção Secundária ou de Média Complexidade, as ações e serviços têm o objetivo de atender problemas e agravos da saúde, cuja demanda necessita de tecnologia e profissionais especializados para apoio de diagnóstico e tratamento. Esse nível de atenção está disponível nos hospitais, Unidades de Pronto Atendimento (UPA), atendimento especializado ambulatoriais, unidades de urgência e emergências. A administração desse nível e organizada através das macro e microrregiões de cada Estado (BRASIL, 2011). No terceiro nível de atenção em saúde 
estão agrupados os procedimentos que demandam alta tecnologia, em que os custos são mais altos e profissionais especializados e tem como objetivo oferecer à população um serviço de qualidade integrado a outros níveis da saúde como atenção básica e secundária. Notamos neste modelo tripartido a importância da ideia de saúde próxima ao usuário e que respeite sua realidade, certamente apontando o caráter local, cultural e social que fundamenta as estratégias do SUS.

Nos anos 1980, uma grande mudança metodológica passou a permear o debate em saúde pública, centrada em uma nova visão de ser humano complexo e integral, no qual o termo biopsicossocial passa a ser amplamente utilizado, como a Conferência Nacional de Saúde, realizada em Ottawa em 1986. Tal conferência foi seminal para postular a ideia de saúde como qualidade de vida resultante de complexo processo condicionado por vários fatores tais como: alimentação, justiça social, ecossistema, renda e educação. Nesse mesmo ano, merece destaque, o relatório final da VIII Conferência Nacional de Saúde como direito à saúde significa a garantia, pelo Estado, de condições dignas de vida (NUNES, SANTOS e BARATA, 2001). O acesso universal e igualitário às ações e serviços de promoção, proteção e recuperação da saúde, em todos os seus níveis, a todos os habitantes do território nacional, levando ao desenvolvimento pleno do ser humano em sua individualidade (BRASIL, 1996).

Além disso, a Agenda de compromissos para a saúde integral da criança e redução da mortalidade infantil (BRASIL, 2010) ressalta de medidas de prevenção e intervenção para este fim, bem como a capacitação das equipes de saúde para identificação de situações de risco desde o período pré-natal até aos cuidados com o recém-nascido. Entre as principais linhas de cuidado descritas na política anteriormente referida, destacam-se: Atenção humanizada e qualificada à gestante e ao recém-nascido; estratégia de acolhimento mãe-bebê na unidade básica após a alta da maternidade, a qual tem como principal objetivo o estabelecimento do vínculo precoce da família com a unidade básica de saúde (UBS) mais próxima de sua residência, quando ao sair da maternidade a mãe recebe um cartão de referência da UBS que fará o acompanhamento de sua saúde e de seu bebê. Acrescenta também, a consonância deste estudo com a Agenda Nacional de Prioridades de Pesquisa em 
Saúde (ANPPS). A agenda é um documento utilizado como instrumento de gestão, o qual o Ministério da Saúde (MS) detalha as prioridades de pesquisa para esse campo, objetivando aumentar a seletividade e a capacidade de indução de iniciativas de fomento à pesquisa no País. A ANPPS tem o objetivo de respeitar as necessidades nacionais e regionais de saúde e incentivar a produção de conhecimentos, bens materiais e processuais nas áreas prioritárias para o desenvolvimento das políticas sociais (BRASIL, 2015).

A popularização do sistema de saúde já buscava em sua implementação romper com o modelo biomédico, hospitalar e farmacêutico de saúde (CARVALHO, 1992). As iniciativas de "saúde de proximidade", como o Estratégia de Saúde da Família (ESF) e a estratégia da saúde mental (NASF) buscavam englobar o sistema de saúde a partir de uma visão mais humana e antropológica sobre o tema (KNAUTH, 1991).

\section{SAÚDE E DOENÇA: PARA ALÉM DO HOSPITAL E MÉDICOS}

Ao afirmamos a importância de entendermos a representação social de saúde e doença nos baseamos na compreensão de que $70-90 \%$ dos episódios de doença são manejados fora dos serviços tradicionais de saúde (KLEINMAN et al., 1978; KLEINMAN, 1980), e em muitos casos são tratados a partir de práticas e crenças "não científicas ou médicas". A relação entre o enfermo e o agente de cura não pode ser compreendida apenas através da demanda aos atendimentos biomédicos, pois tais relações também englobam processos religiosos, místicos, artísticos, crenças populares, automedicação etc. (KLEINMAN, 1986). Assim, quando falamos em processos de doença e cura não estamos apenas interessados em investigar o "impacto da cultura" na busca por serviços de saúde, mas sim como a cultura enquanto sistema de significados, sentidos e valores (GEERTZ, 2003) estabelece a categoria de doença no corpo e aponta as possíveis vias de cura. Deste modo, concordamos com a perspectiva adotada por Geertz (2008) ao descartar uma concepção estratificadora da relação entre as dimensões biológica, psicológica e social/cultural na vida humana, em favor de uma visão em que se leva em conta a contínua interação entre os fenômenos culturais e biológicos que presidiu o processo 
de nossa própria constituição enquanto uma espécie, isto é, a não estratificação dos fenômenos culturais abaixo ou acidentais às manifestações biológicas existentes.

Ao inserirmos o binômio saúde e doença dentro do cuidado com o corpo, torna-se necessário levar em conta as diferentes maneiras como cada grupo social percebe e experimenta estas noções. Autores como Foucault (2010) e Boltanski (1984) foram incisivos ao apontar as relações de poder e o desempenho de papéis sociais relacionados a classe social na construção dos serviços de saúde. Os estudos de Csordas (2008), que formula o paradigma da corporeidade - embodiment-através do exame crítico de duas teorias da corporeidade, quais sejam, a de Merleau Ponty (1999) através da problemática da percepção e de Bourdieu (1984), constituem inegável contribuição para a antropologia do corpo e da saúde ao analisar fenômenos religiosos de cura em cultos protestantes carismáticos nos Estados Unidos. Estudo de Minayo (1994), voltado mais especificamente para o contexto brasileiro, tematiza as noções de doença e cura em um universo de católicos carismáticos. Certamente poderíamos citar uma infinidade de estudos que apontam o processo de cura através da experiência religiosa e mística, e estes são estudos que prolongam uma longa tradição de estudos sobre o tema da saúde nas ciências sociais iniciada por Malinowski (1978), Durkheim (1989), Mauss (2001), Levi-Strauss (1970) entre outros. Deste modo notamos que cada autor procura demonstrar à sua maneira como o cuidado com a saúde constitui um ponto nessa teia de significados que constitui a cultura(GEERTZ, 2008).

\section{CULTURA, SAÚDE E DOENÇAS}

Os estudos clássicos de Mauss (2003) ressaltam a concepção sobre o corpo como parte de processo sociocultural, manifestando um momento histórico específico, no qual o mesmo funciona como um vetor semântico das relações que o homem constrói com si mesmo e com o mundo. Levi-Strauss (1976) também chamou a atenção para o fenômeno da doença e cura como uma possibilidade de a cultura reorganizar a desordem e confusão do corpo através de interpretações que tornem estes estados em um todo coerente. Deste modo, a corporeidade humana não se reduz nem se 
explica apenas por fatores biológicos, sendo estes apenas causas necessárias, mas não suficientes para dar conta do corpo enquanto fenômeno social (OVERING, 1985).

Sabemos que o dualismo cartesiano mente-corpo (MALCON, 1976) é fundante para o sujeito moderno e que a medicina contemporânea o adota como modo hegemônico de paradigma científico. Contudo, autores como Simmel (1971), Durkheim (1978) e Mauss (2003) já haviam chamado a atenção para a separação entre fatos biológicos e culturais como uma característica de nossa cultura ocidental (DUMONT, 1985).

Até mesmo a noção de indivíduo moderno pode ser entendida como uma ideologia que "que reveste a vida dos homens em sociedade, segundo direitos, religiões, costumes, estruturas sociais e mentalidades" (MAUSS, 2003 p. 211). Deste modo, a unidade biológica do corpo é o primeiro e mais importante foco da teoria individualista (DUMONT, 1985). A noção de indivíduo enquanto entidade social, como proposta pela antropologia, nos permite expandir a compreensão dos diferentes itinerários terapêuticos pelo fato de possibilitar a abertura para outros fatores culturalmente inscritos no processo de cura/doença (CSORDAS, 2008).

A partir da perspectiva apontada por estes autores poderíamos presumir enfraquecimento do dualismo cartesiano como fator hegemônico explicativo para a questão da saúde e doença. Contudo, com o advento de novas tecnologias como a clonagem, a manipulação genética e a inseminação artificial o corpo tem sido relegado novamente ao funcionamento mecânico prevalente na medicina desde Descartes (CORRÊIA, 2001).

O imperativo que a noção de "eu" exerce na sociedade contemporânea tem cristalizado a ideia de individuus enquanto entidade não divisível e representada perfeitamente no corpo mecânico (LE BRETON, 2011). Está é uma premissa central no ideário individualista - o indivíduo é um ser único e irredutível (SIMMEL, 1971). Isso tem levado muitos estudos epidemiológicos a conclusões mecanicistas sobre o acesso aos serviços de saúde (POOLE and ROTHMAN, 1998). Por causa dessas aporias conceituais - becos sem saída - cada vez mais as ciências sociais, em especial a Antropologia, tem sido convocado por estudiosos da saúde para desatar os 
nós conceituais com os quais concepções meramente biomédicas têm se confrontado ao investigar a demanda por serviços de saúde (ATKINSON, 1993).

\section{EM BUSCA DA CURA: OS ITINERÁRIOS TERAPÊUTICOS}

Deste modo, um dos grandes desafios atuais é compreender "o corpo como solo existencial do sujeito e da cultura" (CSORDAS, 2008, p. 11) e as consequências disso para a elaboração dos itinerários terapêuticos (IT). Este conceito, conforme proposto pelo antropólogo Augé (1986) busca compreender o caminho percorrido pelo indivíduo na busca de solução para seus problemas de saúde, diante de uma heterogeneidade de recursos. Inserido dentro de um debate maior sobre o conceito de saúde, doença e clínica, seguindo as indicações de Canguilhem (2005) e Foucault (2008), Augé buscava através do saber antropológico desnaturalizar a demanda aos serviços de saúde, visto até então como mera relação racional baseada no viés econômico da oferta e procura. O que os seus estudos seminais, e mais adiante as investigações de Massé (1985) tentavam indicar é o grau simbólico do adoecimento e sua relação direta com a demanda por serviços de saúde, questionando assim a compreensão biologia/médica hegemônica sobre o binômio saúde/doença. Massé (1985) diz sobre - IT que "a procura de cuidados está condicionada tanto pelas atitudes, os valores e as ideologias quanto pelos perfis de doença, o acesso econômico e a disponibilidade de tecnologias" (p. 330).

Nos estudos clássicos de Boltanski (1984), a influência da classe social mostrou-se extremamente relevante para a busca por recursos biomédicos. De modo similar, a noção de habitus proposta por Bourdieu (2001) também nos permite interpretar os itinerários terapêuticos a partir do diálogo com categorias como raça, classe social e ocupação profissional. O comportamento do enfermo (illness behavior), conforme definido por Mechanic \& Volkart na década de 1960 em sua primeira concepção considerava apenas que a escolha do tratamento seria determinada por uma lógica de consumo, recaindo sobre aquele que apresentasse a melhor relação custobenefício para o paciente. Separava ainda as práticas terapêuticas em três categorias: o profissional, constituído pelas práticas formais de exercício da medicina (biomedicina, homeopatia, etc), o popular (cuidados caseiros, autocuidado) ou o folk 
(práticas místicas e religiosas de cuidados) (MECHANIC \& VOLKART, 1961). Contudo, como podemos perceber em recentes estudos multiculturais e principalmente no Brasil (TRAVASSOS et al, 2002; ALVES e SOUZA, 1999; MATTOSINHO e SILVA, 2007; MINAYO, 2006) a lógica do consumo não é a única nem a principal vertente explicativa para o comportamento do enfermo. Além das óbvias diferenças culturais que separam o Brasil dos países anglo-saxões, o acesso gratuito à saúde, a adoção de diferentes ethos religiosos e morais também participam ativamente nas diferentes formas de adoecimento.

O processo que envolve doença e cura torna-se, muitas vezes, para o paciente um ritual de passagem (VAN GENNEP, 2011). Em uma perspectiva antropológica todos os pré-requisitos médicos para a cura são um primeiro momento de separação, denominado de "ritual preliminar" (p. 37). A prática da assepsia, higienização do corpo, a dieta, normalmente prescritas no início dos tratamentos, exercem também uma função simbólica de separação entre os momentos de doença e saúde. Assim, o objetivo da cura passa a não ser apenas a eliminação da doença, mas a transformação do indivíduo (CSORDAS, 2008). Em seus estudos Turner $(1987,1974)$ trabalhou de modo contundente a maneira como os rituais conduzem os indivíduo a determinados estados e atitudes diante o mundo: isolamento de objetos, recombinação de contextos, foco em certas unidades simbólicas e combinação de estímulos sensoriais e intelectuais. Seguindo as indicações de Turner sobre o conceito de performance e ritual Fernandez (1977) afirma que "o ritual deriva sua eficácia e poder de sua performance e é na performance que o trabalho de transformação se realiza" (p. 6).

O cuidado da saúde lida com o dilema acerca do delicado equilíbrio que o paciente deve manter entre a busca a cura e os possíveis riscos envolvidos em procedimentos de saúde (NOVAES, 2012). Douglas e Wildavsky (1983) já haviam chamado a atenção para a impossibilidade de cálculo objetivo do risco aceitável entre doença e os riscos da busca pela saúde. O ponto inconciliável é causado pela tensão entre a percepção subjetiva do corpo e sua definição objetiva elaborada pelos procedimentos científicos. Apesar do corpo parecer apenas uma entidade física objetiva, o mesmo é 
vivenciado como uma imagem subjetiva que se apresenta aos outros. Assim, nossa ideia de imagem corporal também é uma realidade exterior que outros indivíduos intencionam de volta para nós a partir de padrões culturais, formando o que Sartre chamou de "certo tipo de consciência" (SARTRE, 1967, p. 122). É nesta conjunção entre objetividade e subjetividade que se forma a consciência da corporeidade (MERLEAU-PONTY, 1973). É a partir desta construção pessoal e coletiva que o indivíduo escolhe e negocia entre diferentes itinerários terapêuticos.

Ao examinarmos o sistema de saúde e doença através dos itinerários terapêuticos notaremos que a investigação sobre a corporeidade possibilita lançarmos luz ao mesmo tempo sobre aspectos importantes na área da saúde, principalmente sobre o ethos social que constrói ao mesmo tempo os indivíduos e as instituições de saúde (CSORDAS, 2003). Apesar de ser agente ativo na busca por serviços de saúde, o paciente circula entre significados conhecidos e desconhecidos de sua própria cultura, costumes e instituições (MALINOWSKI, 1980). A sociedade brasileira, que tem reservado uma atenção especial para o corpo saudável. Segundo Giacomini (2006) "a aparência - corpo - fala não apenas sobre as condições sociais, mas igualmente do espírito, da moralidade, indissociáveis da aparência" (p. 40). Assim, se por um lado o corpo tem que responder às "demandas naturais", como procriação e sexo, por outro lado ele deve ser cuidado para evitar que apareçam certos aspectos naturais do corpo: o envelhecimento, as rugas, a flacidez e a gordura em excesso.

O corpo e a aparência saudável são, especialmente no Brasil, um verdadeiro capital social, nos termos de Bourdieu (2001). Essa "natureza cultivada" de que nos fala o autor é um corpo trabalhado, saudável, e sua organicidade deve remeter a uma perfeição quase plástica, como no caso das modelos. Deste modo, a aparência do corpo funciona com indícios de posição social (COUTO, 1999). Assim, a doença aparece como uma desordem corporal vinculada à desordem social e até mesmo ao Cosmos. Simmel (1979) chama atenção para correlação entre a vida cotidiana e a visão cosmológica do mundo elaborada por muitos indivíduos, em especial os mais pobres. Apesar de Turner (1974) ter apontado o enfraquecimento de tais compreensões cosmológicas sobre a doença em sociedades modernas e capitalistas 
este fenômeno não parece ter sido mitigado de modo contundente na cultura brasileira (DUARTE, 2006), não sendo incomum encontrarmos entre a população explicações místicas, religiosas, supersticiosas sobre a doença e cura.

\section{DOENÇA INDIVIDUAL, PROBLEMA COLETIVO}

Um ponto importante desta investigação é a compreensão da doença enquanto acontecimento individual, mas também familiar. Diversos autores como Alves e Souza (1999), Camargo (2005) e Rabelo (1993) tem enfatizado o papel da rede familiar e comunitária no cuidado com a saúde de seus membros. Certamente cada membro da família mobiliza uma rede de suporte diferente, mas devemos considerar a doença também como uma mudança na organização familiar. Tomando a família no Brasil como referência Sarti (1996) aponta principalmente um universo de valores em que "os elos de ligações devem prevalecer sobre os projetos individuais" (p. 56), principalmente nos grupos familiares mais pobres, a doença de um membro da família e seu processo em busca da cura torna-se uma verdadeira "tarefa familiar" no qual todos os membros do grupo possuem tarefas específicas.

Destaca-se ainda não apenas a influência da família sobre seus membros, mas também a relação da família com o conjunto das relações sociais. DaMatta (1987) chama a atenção para este ponto fundamental: a relação familiar como paradigma para a compreensão das relações sociais no Brasil. A família enquanto valor central na sociedade brasileira nos permite compreender algumas premissas essenciais a respeito dos itinerários terapêutico uma vez que lança luz sobre a relação dos indivíduos com a res publica - a coisa pública. Isso porque a relação dos indivíduos com as instituições públicas e sociais são fortemente marcados pela lógica pessoal de base familista. Assim, se um membro da família está doente todos os membros da família tem o dever moral de acionar suas redes de contatos em busca de auxílio, não sendo raro o relato de pacientes que conseguiram atendimento através de ajuda de "um conhecido/amigo/colega" que trabalha em determinado serviço público de saúde. 


\section{NAVEGANDO ENTRE AS INSTITUIÇÕES DE SAÚDE}

Uma vez lançado no espaço público em busca de serviços de saúde os indivíduos se utilizam de vários modelos de navegação social: o clientelismo, o personalismo, a malandragem, evitando ao máximo cair nos processos burocráticos e suas artimanhas de exclusão e desassistência, principalmente entre os mais pobres. Uma vez que os serviços públicos de saúde não são garantidos para todos de modo justo, cumprir os protocolos institucionais de agendamento, encaminhamento e atendimento pode parecer improdutivo diante de intermináveis filas e falta de recursos financeiros e humanos. Para resolver tal dilema muitos indivíduos buscam resolver o problema através de relações pessoais (GERHARDT, 2006). Neste modo de navegação social - a esperteza e a malandragem - são estratégias que podem ser mobilizadas em determinadas circunstâncias, como modo de viver, e às vezes sobreviver (DAMATTA, 1998).

Outro ponto importante ao falarmos sobre a entrada dos indivíduos nas instituições de saúde é voltarmos nossa atenção sobre como as instituições de saúde administram as demandas da população, buscando harmonizar os interesses dos pacientes com a metodologia médica de trabalho. Apesar de o viés essencialmente mecanicista biológico dominar os processos de doença e saúde, Giddens (1991) tem apontado que as instituições de saúde tem aberto brechas para discursos como as medicinas alternativas de inspiração oriental, o reavivamento da medicina popular, e o discurso da medicina social e da epidemiologia que colocam em pauta o caráter multifacetado e processual das doenças. Em outro sentido, no Brasil os programas de atenção básica, como o Programa Saúde da Família - PSF - tem buscado aproximar o saber médico da realidade da população mais pobre, enfatizando a saúde como processo multidisciplinar e multifatorial (GUERIN, ROSSONI e BUENO, 2012). Uma vez que resoluções legais, como a Resolução CNE/CES №. 3, estabelecem que os profissionais de saúde atuem pautados na compreensão da natureza humana, reconhecimento de formas e estruturas de organização social e contexto social podemos compreender o impacto do campo sociológico na formação dos novos profissionais de saúde (BRASIL, 1993). 
A abertura para a revisão de alguns pressupostos fortemente estabelecidos no campo da saúde foi preconizada pela Constituição de 1988 através da construção do SUS como um sistema de cuidado da saúde centrado com grande viés sociológico. O atendimento em saúde baseado na "humanização", na prevenção e promoção da saúde buscou criar um sistema atento aos fatores externos ao indivíduo, como o saneamento básico, moradia, alimentação, emprego etc. Deste modo a uma visão antropológica dos serviços de saúde também nos permite uma compreensão sociológica sobre uso destes serviços, sobre as políticas sociais de saúde e da luta pelos direitos fundamentais preconizados no texto constitucional (SANTOS, 2013). indivíduo enquanto protagonista da demanda por saúde encontra-se frequentemente vinculado a ONGs, movimentos sociais, associações de moradores e demais atores sociais que demandam melhores serviços de saúde (TOLEDO, 2013).

As instituições de saúde estão em frequente contato com outras instituições públicas e particulares que a todo tempo demandam ações e serviços de saúde. O progresso da "judicialização da saúde" (CHIEFFI e BARATA, 2009), os encaminhamentos para a investigação médica e psicológica dos casos de indisciplina demandados pelas escolas e colégios (PATTO, 1990), as investigações solicitadas pelo Conselho Tutelar a respeito de casos de negligência dos responsáveis com seus tutelados (MIRANDA e ZAMORA, 2009) são apenas alguns dos exemplos que poderíamos explorar para demonstrar que muitas das vezes as demandas por serviços públicos de saúde e os possíveis itinerário terapêutico são também enredados pelas lógicas de funcionamento institucional.

\section{POR UMA ANTROPOLOGIA DAS POLÍTICAS PÚBLICAS DE SAÚDE PÚBLICA}

O cotidiano da população brasileira é permeado por políticas públicas, que podem ser compreendidas como normas e diretrizes que norteiam as atuações de planos, projetos e orientam práticas governamentais em vários setores e regiões da sociedade (ANTUNES, 2016). Elas emergem de uma demanda da sociedade em resposta a uma problemática instalada ou crescente em algumas áreas, como a da saúde, da 
assistência social e da educação, por exemplo. Esse problema pode ser do cotidiano e a população não perceber, já que lida com ele todos os dias, ou aparecer repentinamente, como uma catástrofe natural.

As políticas públicas podem ser entendidas como um ciclo que se modifica ou não no decorrer de sua elaboração e implantação. Este ciclo pode apresentar cinco fases: 1) a percepção do problema; 2) a questão em análise é incluída na agenda formal; 3) definição e análise do problema em questão e formulação de alternativas para resolver a demanda e decidir qual melhor direção a seguir; 4) a implantação da melhor alternativa, nesta fase estão as negociações entre os diversos setores e atores políticos e 5) avaliação e retificação (ou extinção) das políticas (GELINSKI \& SEIBE, 2008).

Os movimentos sociais possuem um papel fundamental na sociedade brasileira, pois é através das lutas de grupos organizados contra as desigualdades sociais, por melhores condições de saúde, educação, trabalho, moradia etc., que muitas vezes são institucionalizadas as políticas públicas. O relatório da $8^{\text {a }}$ Conferência Nacional de Saúde esclarece que a saúde é a resultante das condições de alimentação, habitação, educação, renda, meio ambiente, trabalho, transporte, emprego, lazer, liberdade, acesso e posse da terra e acesso a serviços de saúde. É, assim, antes de tudo, o resultado das formas de organização social da produção, que podem gerar desigualdades nos níveis de vida. A $8^{\underline{a}}$ Conferência Nacional de Saúde obteve um importante número de representantes sociais em sua assembleia. Seu relatório serviu como base para a promulgação da Constituição Federal do Brasil em 1988, sendo um marco da redemocratização. A Constituição proporcionou uma nova definição de políticas públicas dos estados e da saúde, possibilitando que posteriormente fosse criada a Lei 8.080, de 19 de setembro de 1990, que regulamenta o SUS. Uma das premissas desta lei é a de que o Estado é responsável pela saúde, por meio de políticas públicas sociais e econômicas, que tem como objetivo diminuição de risco de doenças e de outros agravos. Além disso, estabelece que a toda a população tenha acesso universal e igualitário à promoção, proteção e recuperação da saúde (SOUSA, 2014, BERNARDO \& CINTRA, 2017). 
Por último está investigação nos possibilita através do olhar antropológico, uma avaliação das políticas públicas de saúde. O campo das políticas públicas têm sido de modo tradicional tratado como uma subárea das ciências políticas (FREY, 2000), o que tem levado a implementação destas políticas a partir de um viés pretensamente neutro, apolítica, tecnocrata, presidida por metas, valores e objetivos "racionais", no sentido weberiano do termo (LIMA e CASTRO, 2015). Contudo, autores como Teixeira \& Souza Lima (2010) tem apontado o frutífero diálogo entre a Antropologia e as políticas públicas. A partir da experiência do usuário investigado através do método etnográfico podemos analisar o processo de mudança do Estado brasileiro no que diz respeito às políticas de saúde, de modo a compreender como os indivíduos vivenciam os modos do governo "fazer-se Estado" através das políticas públicas.

Como exemplo da aplicação da reflexão antropológica no campo das políticas públicas podemos citar os estudos de Hart (1971) e seu princípio denominado de inverse care law - inversão da lei de cuidado - que diz que a disponibilidade de bons cuidados médicos tende a variar inversamente com a necessidade da população atendida. Assim, os serviços e equipamentos de saúde pública são distribuídos de modo inverso pela cidade. As regiões mais carentes de assistência médica recebem menos serviços nesta área. De modo inverso, a população que menos precisa dos serviços de saúde pública, pois se utilizam dos serviços de saúde complementar - os planos de saúde - são as que mais tem acesso a postos de saúde, hospitais, médicos e equipamentos.

O estudo realizado por Gouveia, Travassos e Fernandez (1997) demonstraram através de uma análise histórica o impacto do SUS na demanda e acesso aos serviços de saúde no estado do Rio de Janeiro entre os anos de 1992 e 1995 e aponta que além da distribuição desigual dos serviços pelo território do estado, os investimentos em saúde também acompanham a mesma lógica, fazendo ruir aos poucos os hospitais e pontos de atendimento já existentes. Poderíamos acrescentar a está mesma lógica inversa de distribuição de serviços públicos a rede de serviços hídricos (PORTO, 1997), sanitários (ALMEIDA, PORTO e BATISTA, 2000), de segurança 
pública (ISP, 2010) entre muitos outros serviços públicos, o que resulta em um maior perfil de adoecimento e mortalidade entre os pobres urbanos (CASTELLANOS, 1997).

As consequências diretas da desigual distribuição de bens e serviços públicos de saúde pelas cidades brasileiras são fundamentais para nossa reflexão, uma vez que os itinerários terapêuticos são percursos de ordem simbólica, mas também socioeconômica. Assim sendo, devemos levar em conta que os usuários dos serviços públicos de saúde são bem heterogêneos, mas segundo os dados do IBGE (2012) a maioria dos atendimentos são prestados a população provenientes das camadas populares e que não tem plano de saúde, o que representa, por exemplo, $70 \%$ da população do estado do Rio de Janeiro (ANS, 2016). Isso tem como consequência o insulamento de grande parte da população dos serviços públicos de saúde que funcionam e tem capacidade operativa real, obrigando os mais pobres a muitas vezes atravessarem a cidade em busca de atendimento médico e hospitalar. Tal situação modifica de modo extremo a busca por auxílio em saúde, determinando muitas das vezes dias, horários e datas específicas para ir ao atendimento em saúde.

\section{CONCLUSÃO}

O sistema de saúde pública ainda carece da constituição de uma agenda política que articule a comunidade de pesquisadores da área, os burocratas do governo, os prestadores de serviços (médicos, enfermeiros, psicólogos etc.) e finalmente os usuários do sistema (ARRETCHE, 2003). Como o Estado detém o monopólio da autoridade, nos interessa investigar em que sentido as políticas públicas de saúde, enquanto projeção de um programa de metas que inclui valores e práticas do Estado (HARRISON, 1987), revelam as ideologias presentes no estado brasileiro. Se a Constituição cidadã de 1988 preconizou a saúde como um direito fundamental foi através do Estado-como-ideia (SOUZA LIMA, 2003). Sem dúvida, nos interessa saber como a busca pelos serviços públicos de saúde são afetados pela maneira como 0 sistema-de-Estado tem atuado quanto aos direitos à saúde elencado na Constituição.

Apesar do acesso aos serviços de saúde terem sido transformados nos últimos 30 anos através da implementação do SUS no Brasil, as mudanças propostas não foram 
homogêneas ou igualitárias para a população de modo geral (TRAVASSOS et al, 2000), em especial para os moradores das periferias das grandes cidades (GERHARDT, 2006). Além disso, a Constituição de 1988 preconizou a municipalização de muitos serviços de saúde, assim como incube ao estado e ao governo federais outras atividades no campo da assistência à população (LIMA et al, 2002). Contudo, a presença significativa de hospitais, postos de saúde etc. não significou um aumento marcante de acesso aos serviços médicos para a população em geral (ASSIS, VILLA e NASCIMENTO, 2003). Cabe-nos enfatizar a importância da harmonia entre os sistemas de atenção à saúde e os sistemas culturais. No final, podemos afirmar que somos todos indivíduos de determinada cultura, vivenciando várias formas de adoecer e buscar uma cura.

Por fim, as principais conclusões que podemos extrair do diálogo entre a Antropologia e os serviços de saúde pública dizem respeito ao enorme impacto que o conceito de humanização do atendimento teve a partir da criação do SUS, o debate sobre a influência da cultura na construção do atendimento ao usuário, deixando de ser um complemento ao sujeito e passando a ser parte constituinte do mesmo. Podemos também ponderar sobre a relação dialógica entre indivíduo e sociedade, muitas das vezes mediado pela família e pelas instituições, que tanto participam de nossas escolhas, crenças, convicções e comportamentos no que diz respeito ao processo de adoecimento e busca pela cura. Passamos então ao debate sobre os serviços públicos de saúde enquanto processos de proximidade da vida cotidiana das pessoas, talvez a maior mudança na saúde, ao encarnar ideal antropológico do saber/fazer não sobre o local, mas no local em que o usuário reside, implementando assim programas de saúde da família e congêneres. Por fim, devemos destacar as contribuições da Antropologia para o campo das políticas públicas de saúde, no qual devemos privilegiar o debate biomédico com as práticas de saúde locais, resgatando e revalorizando as práticas terapêuticas e saberes locais, valorizando o saber autóctone, no qual as práticas de auto atenção empreendidas pelos sujeitos de determinada cultura, valorizando assim as ações de saúde que respeitem os processos individuais e coletivos em suas vivências na saúde e na doença. 


\section{REFERÊNCIAS BIBLIOGRÁFICAS}

ALMEIDA, C., TRAVASSOS, C., PORTO, S., LABRA, M. E. Health Sector Reform in Brazil: A Case Study of Inequity. International Journal of Health Services, Volume 30, Number 1, Pages 129-162, 2000.

ALVES, P. C. B, SOUZA, I. M. Escolha e avaliação de tratamento para problemas de saúde: considerações sobre o itinerário terapêutico. In: RABELO, M. C, ALVES, P. C. B, SOUZA, I. M. A, (org). Experiência de doença e narrativa. Rio de Janeiro: Editora Fiocruz, p. 125-38, 1999.

ANS - Agência Nacional de Saúde. Sistema de Informações de Beneficiários. ANS/MS -12/2016 e População - IBGE/DATASUS/2012. Disponível em: http://www.ans.gov.br/perfil-do-setor/dados-gerais

ANTUNES, Flávia. O Ciclo de Políticas Públicas. Governo do Estado de Pernambuco: Gestão em pauta, 2016.

ARRETCHE, M. Dossiê agenda de pesquisas em políticas públicas. Revista Brasileira de Ciências Sociais (Impresso), São Paulo, v. 18, n.51, p. 7-9, 2003.

ASSIS, M.M.A.; VILLA, T.C.S.; NASCIMENTO, M.A.A. Acesso aos serviços de saúde: uma possibilidade a ser construída na prática. Ciênc. Saúde Coletiva, Rio de Janeiro, v.8, n.3, p.815-823, 2003.

ATKINSON, S. Anthropology in research on the quality of health services. Cad. Saúde Públ., v.9, n.3, p.283-99, 1993.

AUGÉ, M. L'anthropologie de la maladie. L'Homme, Paris, v.26, n.1-2, p.81-90, 1986.

BERGER, Peter L.; LUCKMANN, Thomas. A construção social da realidade: tratado de sociologia do conhecimento. 22. ed. Petropolis: Vozes, 2002. 
BOING, Elisangela; CREPALDI, Maria Aparecida. O psicólogo na atenção básica: uma incursão pelas políticas públicas de saúde brasileiras. Psicol. cienc. prof., Brasília, v. 30, n. 3, p. 634-649, Sept. 2010.

BOLTANSKI, L. As classes sociais e o corpo. Rio de Janeiro: Graal, 1984.

BOURDIEU, P. A economia das trocas simbólicas. São Paulo: Perspectiva, 2001.

BOURDIEU, P. Esboço de uma teoria da prática. Precedido de três estudos de etnologia cabila.Editora Asa, 1984.

BRASIL, Presidência da República. Lei Orgânica da Assistência Social, n. 8.742, de 7 de dezembro de 1993, publicada no DOU de 8 de dezembro de 1993.

BRASIL. Conselho Nacional de Secretários de Saúde. Sistema Único de Saúde / Conselho Nacional de Secretários de Saúde. - Brasília: CONASS, 2011.

BRASIL. Decreto n. 9.394, de 20 de dez. de 1996. Estabelece as diretrizes e bases da educação nacional. Brasília, DF, 1996.

BRASIL. Ministério da Saúde. Humaniza SUS: Política Nacional de Humanização: A humanização como eixo norteador das práticas de atenção e gestão em todas as instâncias do SUS. Brasília, Secretaria-Executiva, Núcleo Técnico da Política Nacional de Humanização, 2004.

BRASIL. Ministério da Saúde. Secretaria de Ciência, Tecnologia e Insumos Estratégicos. Departamento de Ciência e Tecnologia. Agenda nacional de prioridades de pesquisa em saúde. Departamento de Ciência e Tecnologia. 2.ed. Brasília, 2015.

BRASIL. Ministério da Saúde. Secretaria de Vigilância em Saúde. Departamento de Análise de Situação de Saúde. Saúde Brasil 2009: uma análise da situação de saúde e da agenda nacional e internacional de prioridades em saúde. Brasília: Ministério da Saúde; 2010. 
BRASIL. Ministério da Saúde. Secretaria de Vigilância em Saúde. Departamento de Vigilância de Doenças e Agravos Não Transmissíveis e Promoção da Saúde. Saúde Brasil 2014: uma análise da situação de saúde e das causas externas. Brasília: Ministério da Saúde; 2015.

CAMARGO JR, K.R. Das necessidades de saúde à demanda socialmente constituída. In: PINHEIRO, R.; MATTOS, R.A. (Org.). Constituição social da demanda. Rio de Janeiro: Cepesc, 2005. p.91-101.

CANGUILHEM, G. O normal e o patológico. 5. ed. rev. e aum. Rio de Janeiro: Forense-Universitaria, 2005.

CARVALHO, C. de C. M. A doença da saúde tem cura. Saúde em Debate 35, 1992.

CASTELLANOS, P. L. Perfis de mortalidade, nível de desenvolvimento e inequidades sociais na região das Américas, pp.137-160. In RB Barata et al. (orgs.). Equidade e Saúde: Contribuições da Epidemiologia. Fiocruz/Abrasco, Série Epidemiológica 1, Rio de Janeiro, 1997.

CHIEFFI, A. L., E BARATA, R. B. Judicialização da política pública de assistência farmacêutica e eqüidade. Cad. Saúde Pública, Rio de Janeiro, 25(8):1839-1849, ago, 2009

CINTRA, Marcela Spinardi; BERNARDO, Marcia Hespanhol. Atuação do Psicólogo na Atenção Básica do SUS e a Psicologia Social. Psicol. cienc. prof., Brasília, v. 37, n. 4, p. 883-896, dez. 2017.

COHN, A., and ELIAS, P. Saúde no Brasil: políticas e organização de serviços. Cortez Editora, São Paulo, 1996.

CORRÊIA, M. V. Novas tecnologias reprodutivas: limites da biologia ou biologia sem limites? Rio de Janeiro: Eduerj, 2001.

COUTO, E. S. Estética e Virtualização do Corpo. Revistas Fronteiras, estudos midiáticos, v.1, n.1, pp.63-75, 1999. 
CSORDAS, T. Corpo, significado, cura. Porto Alegre, Editora da UFRGS, 2008.

CSORDAS, T. Embodiment and experience. Cambridge, Cambridge University Press, 2003.

DAMATTA, R. A Família como Valor: Considerações não-familiares sobre a Família Brasileira. In: Espaço e Tempo. (Org.). Pensando a Família no Brasil: da Colônia a Modernidade. Rio de Janeiro: Espaço e Tempo, 1987

DAMATTA, R. Carnavais, malandros e heróis: para uma sociologia do dilema brasileiro. 6. ed. Rio de Janeiro: Rocco, 1998.

DOUGLAS, M., WILDAVSKY, A. Risk and Culture. An Essay on the Selection of Technological and Environmental Dangers. Universty of California Press, 1983.

DUARTE, L. F. D. Ethos privado e modernidade: o desafio das religiões entre o indivíduo, família e congregação. In: DUARTE, L. F. et al. (Orgs.). Família e religião. Rio de Janeiro: Contra Capa, 2006.

DUMONT, L. 0 individualismo: uma perspectiva antropológica da ideologia moderna. Rio de Janeiro: Rocco, 1985.

DURKHEIM, E. As Formas elementares de vida religiosa: o sistema totêmico na Austrália. São Paulo: Edições Paulinas, 1989.

DURKHEIM, E. O suicídio: um estudo sociológico. Rio de Janeiro: Zahar, 1989.

FERNANDEZ, J. "The performance of ritual metaphors". In: J. SAPIR \& J. COCKER (eds.). The social use of metaphor. Pennsylvania, The University of Pennsylvania Press, 1977.

FERRAZZA, Daniele Andrade. Psicologia e políticas públicas: desafios para superação de práticas normativas. Rev. Polis e Psique, 2016; 6(3): 36 - 58. 
FOUCAULT, M. Arqueologia das ciências e história dos sistemas de pensamento. 2. ed. Rio de Janeiro: Forense Universitária, 2008.

FOUCAULT, M. O nascimento da clínica. 5. ed. Rio de Janeiro: Forense Universitária, 2010.

FREY, K. "Políticas Públicas: um debate conceitual e reflexões referentes à prática da análise de políticas públicas no Brasil". Planejamento e Políticas Públicas, 21:211$259,2000$.

GARNELO L, LANGDON, E.J. A Antropologia e a reformulação das práticas sanitárias na atenção básica à saúde. In: Minayo MCS, Coimbra $\mathrm{C}$, organizadores. Críticas e atuantes: ciências sociais e humanas em saúde na América Latina. Rio de Janeiro (RJ): Editora Fiocruz; 2005.

GEERTZ, C. A interpretação das culturas. Rio de Janeiro: Guanabara Koogan, 2008.

GEERTZ, C. O saber local: novos ensaios em antropologia interpretativa. Petrópolis: Vozes, 2003.

GELINSKI, Carmen Rosario Ortiz G.; SEIBEL, Erni José. Formulação de políticas públicas: questões metodológicas relevantes. Revista de Ciências Humanas, v. 42, n. 1 e 2, p. 227-240, 2008.

GENNEP, A. van. Os ritos de passagem. Petrópolis: Vozes, 2011.

GERHARDT, T. E. Itinerários terapêuticos em situações de pobreza: diversidade e pluralidade. Cad. Saúde Pública, Rio de Janeiro, v.22, n.11, p.2449-2463, 2006.

GIACOMINI, S. M. A alma da festa: família, etnicidade e projetos num clube social da Zona Norte do Rio de Janeiro O Renascença Clube. Belo Horizonte: Ed. UFMG; Rio de Janeiro: IUPERJ, 2006.

GIDDENS, Anthony. As consequências da modernidade. São Paulo: UNESP, 1991. 
GOUVEA, C. S. D. de; TRAVASSOS, C.; FERNANDES, C. Produção de serviços e qualidade da assistência hospitalar no Estado do Rio de Janeiro, Brasil - 1992 a 1995. Rev. Saúde Pública, São Paulo, v. 31, n. 6, p. 601-617, Dec. 1997.

GUERIN, G. D.; ROSSONI, E.; BUENO, D. Itinerários terapêuticos de usuários de medicamentos de uma unidade de Estratégia de Saúde da Família. Ciênc. saúde coletiva, Rio de Janeiro, v. 17, n. 11, p. 3003-3010, Nov. 2012.

HARRISON, W. "Política (policy)". In SILVA, Benedito (ed.): Dicionário de Ciências Sociais, pp.921-922. Rio de Janeiro: Editora da FGV, 1987.

HART, J. T. The inverse care law. The Lancet 1 (7696): 405-412, February 27, 1971.

IBGE-Instituto Brasileiro de Geografia de Estatística. Pesquisa Nacional por Amostra de Domicílios (PNAD). Rio de Janeiro, IBGE, 2012.

ISP - Instituro de Segurança Pública. Dados sobre o número de delegacias e batalhões x população no Estado do Rio de Janeiro, 2010.

KLEINMAN, A. Patients and healers in the context of culture. Berkeley: University of California Press, 1980.

KLEINMAN, A. Social origins of distress and disease: depression, neurasthenia and pain in modern China. New Haven: Yale University Press, 1986.

KLEINMAN, A., EISENBERG, L., GOOD, B. Culture, illness and care: clinical lessons from anthropologic and cross-cultural research. Ann. Int. Med., v.88, n.2, p.251-8, 1978.

KNAUTH, D. Os caminhos da cura: sistema de representações e práticas sociais sobre doença e cura em uma vila de classes populares. Porto Alegre, 1991. Dissertação (Mestrado) Universidade Federal do Rio Grande do Sul.

LE BRETON, D. A sociologia do corpo. Rio de Janeiro: Vozes, 2010. 
LE BRETON, D. Adeus ao corpo: antropologia e sociedade. 5. ed. Campinas: Papirus, 2011.

LÉVI-STRAUSS, Claude. Antropologia estrutural. 2. ed. -. Rio de Janeiro : Tempo Brasileiro, 1970.

LÉVI-STRAUSS, Claude. O pensamento selvagem. São Paulo: Ed. Nacional, 1976. LIMA, A. C. DE S. E CASTRO, J. P. M. Notas para uma Abordagem Antropológica da(s) Política(s) Pública(s). Revista Anthropológicas, ano 19, 26(2):17-54, 2015.

LIMA, J. C. et al. Desigualdades no acesso e utilização de serviços de saúde no Brasil. Saúde Debate, Rio de Janeiro, v.6, n.60, p.62-70, 2002.

MALCOLM, N. Problems of mind: Descartes to Wittgenstein. London: G. Allen, 1976. MALINOWSKI, B. Argonautas do Pacífico Ocidental: um relato do empreendimento e da aventura dos nativos nos arquipélagos da Nova Guiné Melanésia. 2. ed. São Paulo: Abril Cultural, 1978.

MALINOWSKI, B. Uma teoria científica da cultura. Rio de Janeiro: Zahar, 1980.

MARCONI, M. A.; LAKATOS, E. M. Técnicas de pesquisa: planejamento e execução de pesquisas, amostragens e técnicas de pesquisas, elaboração, análise e interpretação de dados. 5ª ed. São Paulo: Atlas, 2002.

MASSÉ, R. Culture et santé publique. Les contribuitions de l'anthropologie à la prévention et à la promotion de la santé. Montreal: Gaëtan Morin Éditeur, 1985.

MATTOSINHO, M. M. S, SILVA, D.M.G.V. Itinerário terapêutico do adolescente com Diabetes Mellitus tipo 1 e seus familiares. Rev Latino-am Enfermagem, 15(6):11131119, 2007.

MAUSS, M. Sociologia e Antropologia. São Paulo: Cosac \& Naify, 2003.

MAUSS, Marcel. Ensaios de sociologia. 2. ed. São Paulo: Perspectiva, 2001. 
MECHANIC, D. and VOLKART, E. Stress, illness behavior and the sick role. American Sociological Review, 26, 52, 1961.

MERLEAU-PONTY, M. Ciências do homem e fenomenologia. São Paulo: Saraiva, 1973.

MERLEAU-PONTY, M. Fenomenologia da percepção. São Paulo, Martins Fontes, 1999.

MINAYO, M. C. de S. O Desafio do conhecimento: pesquisa qualitativa em saúde. São Paulo: Hucitec, 2006.

MINAYO, M.C.S. Contribuições da antropologia para pensar a saúde. In: CAMPOS, G.V.S, MINAYO, M.C.S, AKERMAN, M, DRUMOND JUNIOR, CARVALHO, Y. M, organizadores. Tratado de saúde coletiva. São Paulo: Hucitec; 2006. p. 201-230.

MINAYO, M.C.S. Representações de cura no catolicismo popular. In: MINAYO, M.C.S, ALVES, P. C. (Orgs). Saúde e doença: um olhar antropológico. Rio de Janeiro: Editora Fiocruz, 1994.

MIRANDA, P.; ZAMORA, M. H. Direitos Fundamentais de Crianças e Adolescentes em Favelas Cariocas: Problematizando a produção da Negligência. Polêm!ca, v. 8, p. 33-48, 2009.

NOVAES, J. de V. Você tem fome de quê? Sobre a clínica da obesidade em um hospital público. In: VILHENA, J. de, NOVAES, J. de V. (org.) Corpo para que te quero? Uso, abusos e desusos. Rio de Janeiro: PUC-Rio: Appris, 2012.

NUNES A, SANTOS JRS, BARATA RB, VIANNA SM. Medindo as desigualdades em saúde no Brasil: uma proposta de monitoramento. Brasília (DF): Organização Pan-Americana da Saúde, Instituto de Pesquisa Aplicada; 2001.

OTTA, E; QUEIROZ, R. da S. A beleza em foco: condicionantes culturais e psicobiológicos na definição de estética corporal. In: Queiroz, R. da S. (org.). O corpo do brasileiro: estudos de estética e beleza. São Paulo: Senac, 2000. 
PATTO, M.H.S. A produção do fracasso escolar. São Paulo, T.A. Queiroz, 1990.

POLIT, D.F, BECK, C.T. Fundamentos da pesquisa em enfermagem: avaliação de evidências para a prática de enfermagem. $7^{\mathrm{a}}$ ed. Porto Alegre: ArtMed; 2011

POOLE, C., and ROTHMAN, K. J. "Our Conscientious Objection to the Epidemiology Wars." Journal of Epidemiology and Community Health, vol. 52, no. 10, pp. 613614, 1998.

PORTO, S. M. Equidade na distribuição geográfica dos recursos em saúde: uma contribuição para o caso brasileiro. Tese de doutorado. Escola Nacional de Saúde Pública, Fundação Oswaldo Cruz, Rio de Janeiro, 1997.

RABELO, M. Religião e cura: algumas reflexões sobre a experiência religiosa das classes populares urbanas. Cadernos de Saúde Pública, Rio de Janeiro, v.9, n.3, p.316-325, 1993.

SANTOS, M. A. Lutas sociais pela saúde pública no Brasil frente aos desafios contemporâneos. R. Katál, Florianópolis, v. 16, n. 2, p. 233-240, jul./dez. 2013.

SARTI, C. A. A família como espelho: um estudo sobre a moral dos pobres. São Paulo: Editora Autores Associados, 1996.

SARTRE, J. P. A Imaginação. São Paulo: Difusão Européia do Livro, 1967.

SCLIAR, Moacyr. História do conceito de saúde. Physis: Revista de saúde coletiva, v. 17, p. 29-41, 2007.

SIMMEL, G. Essays on interpretation in social science. Manchester: Manchester University Press, 1971.

SIMMEL, G. On Individuality and Social Forms. Chicago: The University of Chicago Press, 1979. 
SOUSA, F. Maria. A Reforma Sanitária brasileira e o Sistema único de Saúde. Tempus Actas de Saúde Coletiva, v. 8, n. 1, p. 11-16, 2014.

SOUZA LIMA, A. C. de. "Introdução: Sobre gestar e gerir a desigualdade: pontos de investigação e diálogo". In SOUZA LIMA, A. C. de (ed.): Gestar e Gerir: Estudos para uma antropologia da administração pública, pp.11-22. Rio de Janeiro: Nuap/RelumeDumará, 2003.

SOUZA, Marcela Tavares de; SILVA, Michelly Dias da; CARVALHO, Rachel de. Revisão integrativa: o que é e como fazer. Einstein (São Paulo), São Paulo, v. 8, n. 1, p. 102-106, Mar. 2010.

TEIXEIRA, C. e SOUZA LIMA, A.C. A antropologia da administração e da governança no Brasil: área temática ou ponto de dispersão? In: C. Martins e L. F. Duarte, Horizontes das Ciências Sociais no Brasil. Antropologia. São Paulo, ANPOCS, pp. 51-96, 2010.

TOLEDO, L. M. de (Org.) Movimentos sociais e saúde. Rio de Janeiro, ENSP/FIOCRUZ, 2013.

TRAVASSOS, C, VIACAVA, F, PINHEIRO, R, BRITO A. Utilização dos serviços de saúde no Brasil: gênero, características familiares e condição social. Rev. Panam Salud Pública, 11(5/6):365-373, 2002.

TRAVASSOS, C. et al. Desigualdades geográficas e sociais na utilização de serviços de saúde no Brasil. Ciência e Saúde Coletiva, Rio de Janeiro, n.5, p.133-149, 2000.

TURNER, V. O processo ritual: estrutura e anti-estrutura. Petrópolis: Vozes, 1974.

TURNER, V. The anthropology of performance. Nova York: PAJ Publications, 1987.

VELHO, G. Individualismo e juventude. Rio de Janeiro: Museu Nacional, 1990.

Enviado: Julho, 2019. 
Aprovado: Agosto, 2019. 